\title{
COLOUR AND HEALING
}

\author{
Dr. Saroj Kothari \\ Professor \& Head, \\ Department of Psychology, Govt. M.L.B.P.G. Girls College, Indore \\ Deepak Jahagirdar \\ Research Scholar (Psychology), Govt. M.L.B.P.G. Girls College, Indore
}

\section{INTRODUCTION}

The effects of colour on life have been of great significance to early human beings, whose very existence was governed by light and darkness. Most living things appear to be vitalized by the bright reds, oranges, and yellows of daylight and calmed and rejuvenated by the blues, indigos, and violets of the night (Graham, 1998). The story of colour is almost the story of civilization itself. Man's love of colour is as old as his time on earth, and it is apparent in his early pottery and art. "Colour acts upon the human body; it is the key touched by man to obtain the appropriate vibration from his creative spirit" (Kandinsky 1914). All nature was coloured and ancient man tried to emulate it, copy it, and symbolize it.

Colour has always been associated with healing, because man related the power of the sun and rainbow to divine forces. For the ancients, the colours that make up sunlight were each considered to show a different aspect of the divine and to influence different qualities of life. Colour is therefore an important feature in the symbolism of ancient cultures throughout the world, and the origins of healing with colour in Western civilization can be traced back to the mythology of Ancient Egypt and Greece. According to Ancient Egyptian mythology, the art of healing with colour was founded by the god Thoth. He was known to the Ancient Greeks as Hermes Trismegistus, literally "Hermes thrice-greatest" because he was also credited with various works on mysticism and magic. Teachings attributedto him include the use of colour in healing in the Hermetic tradition; the Ancient Egyptians and Greeks used coloured minerals, stones, crystals, salves, and dyes as remedies, and painted treatment sanctuaries in various shades of colour.Interest in the physical nature of colour developed in Ancient Greece alongside the concept of the elements-air, fire, water, and earth. These fundamental constituents of the universe were associated with the qualities of coldness, heat, wetness and dryness, and also with four humors of bodily fluids-choler or yellow bile, blood (red), phlegm (white), and melancholy or black bile. These were thought to arise in four organs the spleen, heart, liver, and brain and to determine emotional and physical disposition. Health involved the proper balance of these humors, and diseases would result if their mixture was in an unbalanced proportion. Colour was intrinsic to healing, which involved restoring the balance. Coloured garments, oils, plasters, ointments, and salves were used to treat disease. (Graham, 1998)

Colour is a powerful medium that can stimulate positive emotional reactions, which promotes conditions for recovery. Colour is light-visible radiant energy of certain wavelengths. The word healing comes from the Anglo Saxon word Haelen, which means to make whole (www.ki.com 2011). Healing reduces stress and anxiety, which in turn positively impacts us. Colour has a direct 
influence on our thoughts, moods and behavior. Blind people also effected they are able to sense the energy vibrations within the body.

\section{COLOUR APPLICATION AND HEALING}

Over the centuries, many cultures employed colour for its healing powers. This is not a new concept; colour therapy has been around for over 5,000 years the Ancient Chinese concept FENG SHUI. The history of colour is interlaced with early pioneers in healing and science. From ancient Egypt and the isles of Greece to the ltalian peninsula andthe city of Rome, colour was spoken as one of the languages for health. Pythagoras, Hermes, Hippocrates, Democritus, Aristotle, and Galen, all gave credibility to colour as an "outward expression" of an internal pathological condition. Although centuries apart, the physicians Pythagoras in Greece and Galen in Rome treated with colours. Pythagoras was reported to have used colour and music to cure disease; while Galen believed that external application of colour could encourage the healing of an internal condition. Hippocrates. The renowned physician, who wrote the oath that all medical doctors follow today, found that the colour of a patient's skin determined the condition of their health. His theory was that a flushed or reddened skin indicated circulatory disease; a yellow appearance gave the sign of stomach or liver involvement, and blue to black discoloration of the body showed a terminal illness. He prescribed many treatments and medicines based on his diagnostic attitude toward skin discoloration. In the eleventh-century Persian Islamic philosopher and healer Avicenna the father of colour therapy use colour for diagnosis and cure. In his Canon of Medicine he gave credit to colour as a most important curative; he even wrapped his patients in red bandages to stimulate their circulation for healing. Avicenna was known throughout Europe for his cloak, which he wore as a physician's mantle (Mella, 1988).

The pioneer of modern colour therapy was Niels Finsen of Denmark, following the discovery, in 1877, of the bactericidal action of solar ultra-violet energy; Finsen studied the possibility of assisting the healing of wounds with visible light. He subsequently used red light to inhibit the formation of smallpox scars and in, 1996, founded a Light Institute for the photo treatment of tuberculosis.Colour healing surfaced again in the late nineteenth-century in America due to the efforts of Edwin D. Babbitt, a mystic, artist and physician. Dr. Babbit expounded upon the relationship between colour and medicine. In his journal. The Principles of Light and Colour, published in 1878, he chose the three primaries-red, yellow, and blue-as the basic healing rays of colour. He felt that each colour had an opposite colour that affected the return of balance to the body (Babbit, 1878).In 1932, Gerrard and Hessay, two Californian psychologists, scientifically established that blue light has a calming effect and red light has a stimulating power on human beings. Blue and red colours are considered at the extremes with yellow representing the midpoint. These are also the three principal colours. In a rainbow every substance on earth contains colour. Even the rays cast on earth by celestial bodies contain colour in the form of white light. The rays of the sun contain seven different colours-violets, indigo, blue, green, yellow, orange and red. These are natural colours, which are highly beneficial to the maintenance of health and for healing diseases. 
Until the advent of antibiotics in the late 1930's the use of sunbathing and ultraviolet light were internationally accepted and commonly used medical treatments.Colour Therapy was practiced internationally as well. Even though sunlight has gone put of style studies show children in rooms with full spectrum lighting developed one third less decay then children with standard cool white lighting and have less behavioural problems. One of the better-known tests developed to diagnose patients emotional condition was created in the late sixties by Max Luscher, a Swiss psychologist. His book, "The Luscher Color Test", once intended only for the professional audience, uses color cards psychometrically in sequential series of choice to reveal a person's psychological makeup. Luscher Color Test is useful in medical practice because the test deepens the doctor's understanding of the patients' psychological makeup and enables him to be less biased in his judgments. It gives important indications for use in diagnosis and therapy and also for the prognosis of certain illness (Luscher, 1969). The field of Chromo therapy uses colour as a therapeutic tool for treatments. There have been numerous studies published about colour in healthcare. British colour psychologists Angela Wright states that colour affects us physiologically as well as emotionally. Since colour stimulates the nervous system, it can influence mood and provoke reactions. As a consequence, the use of colour can make environment more peaceful and less anxiety provoking. This translates into a positive mood, which encourages the healing process.(Wright,2011)Faber Birren conducted colour research and determined that bright and vivid colours could arouse and increase autonomic functions, blood pressure, heart and respiration rate. Conversely, dimness and softer colours create an inward response-one of calm and repose. (Birren, 1969, 1982)

\section{COLOUR THERAPY}

Colour is everywhere and whether we realize it or not, colour exerts powerful influences on our decisions, emotions, moods and our physiology. Research reveals people make a subconscious judgment about a person, environment, or product within 90 seconds of initial viewing and that between $62 \%$ and $90 \%$ of that assessment is based on colour alone (www.ki.com 2011). The history of colour therapy is very ancient. This system of therapy was prevalent not only in India but also in Egypt, China, Greece and Persia and also the Vedas and Jain scriptures have mentioned the significance of colours. The practice of colour therapy was on its decline in the middle ages, and new systems of medicine like Ayurveda, Unani, Homeopathy, and Allopathic had started flourishing, attracting people's attention. Colour therapy took a back seat. The twentieth century is the period of revival of colour therapy. There is evidence that it developed most in the U.S.A. The system of colour therapy has prospered in India in the last 70 years. People are now convinced of its miraculous results. The basis of this system is solar energy, the colour and light of the sunrays on which every has a birthright and can use without having to pay for it. The system is absolutely natural and simple. Medicines affected by the rays of the sun are so subtle and powerful that they can cure many diseases. This therapeutic system is closely related to one's body, mind and emotions. The entire human body is a mass of colours. If a part of the body is sick, besides its chemical balance, its colour balance too is affected. Colour therapy restores the chemical and colour balance and cures the disease. 


\section{INTERNATIONAL JOURNAL of RESEARCH -GRANTHAALAYAH

\section{THE TECHNIQUES OF COLOUR THERAPY}

$>$ Solarized Water: Take a clean bottle of the same colour as the medicine to be prepared or a clear glass covered with transparent coloured fabric or cellophane. Fill it with clean drinking water, leaving a small part of the bottle empty. Close the lid and keep it in the sun for 6-8 hours. The water will become infused with the vibrations of the colour of the spectrum tastes different and has a therapeutic effect on a different part of the body. The orange charged medicine is taken after meals. The green and blue medicines are to be taken on an empty stomach or one hour before meals.

$>$ Solarized Sugar: Take a bottle of the colour of the medicine required. Fill half the bottle with dry, granulated sugar or sugar of milk and keep it everyday in the sun for one month.

$>$ Colour Sunbath Radiation from sun-rays: Placing a sheet of coloured cellophane in a sunny window, then sitting in front of the window for ten minutes or so. Stained glass windows or coloured glass panes can give the same therapeutic benefit. Glass, transparent plastic or cellophane of different colours can be used for radiation on any external or internal part of the body.

$>$ Coloured Fabric Swatches: Place the coloured cloth over the area you need to work on. Relax and breathe deeply for one to five minutes. It can be used to balance energy after a stressful day.

$>$ Solarized Sugar Pills: Take a clean bottle of the required colour and half fill it with milk sugar pills no. 20. Keep it out in the sun everyday for three months. Shake the bottle gently everyday so that the pills do not break and the sun-rays fall on the pills properly.

$>$ Oil Medicines: Orange and green bottles with pure mustard or sesame oil and a blue bottle with coconut oil filled half may be kept in the sun for one month without break.

$>$ Colour Meditation: Visualize a colour and imagine it showering down into the top of head, flowing through body, and washing out through feet. It also is flowing into lungs. The energy of the visualize colour produces therapeutic benefits for body.

$>$ Photodynamic Therapy: A new technique, which has been developed over the past two decades as a result of pioneering research, is photodynamic therapy, or PDT. This is based on the discovery that certain intravenously injected photosensitive chemicals not only accumulate in cancer cells but selectively identify these cells under ultraviolet light. These photosensitive chemicals then exclusively destroy the cancer cells when activated by red light, whose longer wavelength allows it to perform it to penetrate tissue more deeply than other colours. PDT can be used for both diagnosis and treatment. Dr. Thomas Dougherty, who developed PDT, reports that in a worldwide experiment more than 3000 people, with a wide variety of malignant tumors, have been successfully treated with this technique.

$>$ Quick Fix Colour Therapy: Colourvibration travels via the nervous system, to the part of the body that needs it. Each body has its own optimum state of well-being and is constantly seeking ways to maintain or restore a balanced state. Gaze at the colour for as long as you feel comfortable, blinking as you need to. Drink in the colour through your eyes until you fill satiated. This may take several minutes. Once satisfied you have absorbed enough of the colour's vibrations, if another colour appeals to you, repeat the process. 


\section{INTERNATIONAL JOURNAL of RESEARCH -GRANTHAALAYAH \\ A knowledge Repository}

Art

> Crystal Healing/Crystal Therapy: Crystal Healing or Crystal Therapy is the laying on of stones to restore balance to the chakra system and heal the physical body, emotions, mental thoughts and the spirit. Stones are placed based on color, quality, and sacred geometry.

$>$ Color-tinted eyeglasses: Color-tinted eyeglasses can be highly effective in the treatment of learning difficulties, notably dyslexia. This was first discovered by psychologist Helen Irlen. In 1993, a new optician's device called the Intuitive Colorimeter was made available to British opticians so they could measure which tint-bright pink, yellow, green or blue-best helps people who normally see text as swirling, wobbling, or with letters appearing in the wrong order.

$>$ Therapeutic Effects of the Colours (Lenhoff, 2004): Colour is light and light is energy. Each colour has a different wavelength, and therefore a different energy. Each colour produces different effects.

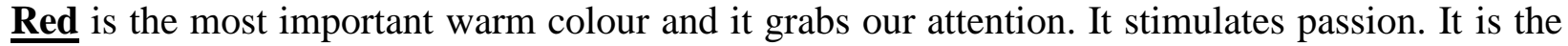
colour of strength, health, courage, vitality, will, anger and power. It is also associated with love, danger and boldness in the face of danger. Red causes the most active physiological response. It raises our heart and respiration rates, blood pressure, and temperature. Red peps up the autonomic nervous system and acts as a stimulant. Red light can be used to treat low blood pressure, eczema, circulatory problems and sore throats.A governor depending of the prison found that the behavior of the prisoners varied significantly depending on which wing they lived in (four wings had been painted a different colour). Those in red and yellow wings were more inclined to violence than those in the blue and green wings.Experimental research found that viewing red light has been increase subjects strength by 13.5 percent and to elicit 5.8 percent more electrical activity in the arm muscles. For this reason it is now used to improve the performance of athletes. Whereas red light appears to help athletes who need short, quick bursts of energy, blue light assists in performances requiring a more steady energy output (Graham, 1998).

Orange connects us to our intuition which is especially valuable in matters of the heart. It is associated with energy, spontaneity, joy and creativity. It is the colour of youth, strength, fearlessness, curiosity and restlessness. Orange is spicy and, like spices, is best used in small amounts.

Yellow is the most reflective and bright of the primary colours and the colour we see first. Yellow is sunny, cheerful, up beet, lively and glowing. It is the colour of happiness, wisdom and imagination. It stimulates thought which makes it suitable for rooms where mental pursuits are undertaken. It was a stimulating effect on the nerves and the solar plexus. Yellow is a muscle stimulant and nerve builder.

Green is associated with balance, harmony, sympathy, diplomacy, adaptability, durability and reliability. It symbolizes hope, renewal and peace. Green light is used for emotional disorders such as anxiety and for infections.

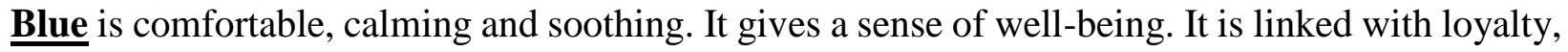
reliability, and high honor. Blue is also the colour of deliberation, introspection, conservatism and duty. Blue light is used to cure infections, headaches, high blood pressure, neonatal jaundice and rheumatoid arthritis. Blue light is also used in healing injured tissue and preventing scar tissue, in the treatment of cancers and nonmalignant tumors, as well as skin and lung conditions. Dr. Edwin 
Babbitt (1967), in his classic, "The Principles of Light and Color," states that "The Blue Ray is one of the greatest antiseptics in the world."

Purple has long been associated with pride, solemnity, pomp, ceremony and royalty. It can also indicate mourning. It combines red's power with blue elegance.

White is the colour of purity, innocence, youth and freshness. White is particularly effective at getting rid of negativity. Bright white full-spectrum light is also being used in the treatment of cancers, seasonal affective disorder/winter depression SAD, anorexia, bulimia nervosa, insomnia, jet lag, shift working, alcohol and drug dependency, and to reduce overall levels of medication and depression.

Colour therapy or colour healing is the use of colour in various forms for the purpose of creating balance and health in the human system. The human system includes not only the physical body, but also the emotional, mental and apiritual aspects (PEMS). Working with the PEMS is referred to as wholisticmedicine.

Each colour has its own wavelength and frequency, the rate at which its wave vibrates. Practitioners of colour therapy believe that cells and organs of the body also have vibrational frequencies; they use colours to correct vibrational imbalance in the body and create a steate of harmony. When the energy of colour enters our bodies, it stimulates the production of certain hormones, which in turn affect a variety of physiological processes. This explains why colour has been found to have such a direct influence on our thoughts, moods and behavior.

\section{REFERENCES}

1- Babbit, Edwin (1878) "The Principles of Light and Color" East Orange NJ.

2- Babbit Edwin (1967) "The Principles of Light and Color" The Citadel Press.

3- Birren, Faber (1969, 1982) "Light, Color \& Environment" Revised Edition, New York; VanNostrand Reinhold Company, Inc.

4- Graham, Helen (1998) "Discover Color Therapy" A history of color therapy, amazon. com.

5- Kandinsky, Wassily (1914) "The Art of Spiritual Harmony” Boston: Houghton Mifflin Co.

6- Laura Guido-Clark Design, LLC (2011) "Color and Healing” The Power of Color in the Healthcare Environment" www.ki.com

7- Lenhoff, Diane (2004) “Color Therapy”www.ega-dayton.webs.com/color therapy.pdf

8- Luscher, Max (1969) “The Luscher Color Test” New York: Pocket Books.

9- Mella L, Dorothee (1988) “The Language of Color" A Warner Communication Company, NY, 10103

10- Wright, Angela (2011) "Healing Hues: Using color to improve health "The Neenan Company Blog, http//blog.neenan.com/! $p=1016$. 